\title{
PERANCANGAN VEKTOR KENDALI SPWM INVERTER SEBAGAI KONTROL MOTOR TURBIN ANGIN PADA GENERATOR INDUKSI 3 FASA
}

\section{Heru Danarbroto}

\begin{abstract}
Abstrak
Metode vektor kontrol SPWM inverter merupakan metode pengaturan vektor tegangan yang digabungkan dengan pengaturan amplitudo dan frekuensi untuk mengendalikan kecepatan motor induksi melalui teknik pengendalian inverter. Pengaturan vektor berfungsi untuk mentransformasikan sistem arus 3 fasa kerangka acuan tetap $(a, b, c)$ menjadi elemen dua fasa kerangka acuan tetap $(\alpha, \beta)$ melalui transformasi clarke. Kemudian dari kerangka acuan tetap diubah menjadi elemen dua fasa kerangka acuan bergerak $(\mathrm{d}, \mathrm{q})$ melalui transformasi park.Didalam sistem 2 fasa inilah analisis vektor ruang dilakukan untuk menghasilkan konfigurasi penyaklaran IGBT pada rectifier atau inverter.

Spacevector PWM ditujukanuntukmembentuktegangankeluarandari PWM converter mendekatiteganganreferensinyamelalui proses switching dari 8 konfigurasipenyaklaran IGBT yang dihasilkandari 6 buah vector yang membentuk 6 interval waktu yang masing-masing tergeser $60^{\circ}$ danduabuahvektortegangannol (zero voltage vectors) yang berada di pusatkoordinat.

Dengan metode ini berhasil meningkatkan efisiensi kerja motor-generator induksi melalui peningkatan kerja inverter 3 fasa jika dibandingkan dengan teknik SPWM ataupun scalar kontrol yang hanya menitik beratkan pada pengendalian frekuensi dan tegangan tanpa mempertimbangkan acuan gerak stator motor.
\end{abstract}

Kata kunci : Space vector control, Rectifier, Inverter, Transformasi Clarke, Transformasi Park.

\section{PENDAHULUAN}

\subsection{Motor Induksi}

Pengendalian motor induksi secara konvensional menyebabkan konsumsi energi listrik tidak efisien, hasil produksi tidak fleksibel, dan sangat mungkin menyebabkan mudah rusaknya motor listrik karena selalu dipaksa bekerja pada kecepatan maksimal. Permasalahan lain adalah munculnya daya reaktif induktif yang menyebabkan menurunnya kualitas daya listrik dan faktor daya dengan impedansi tinggi, serta meningkatnya jatuh tegangan.

Denganberkembanganya

elektronika daya, pengendalian motor arus bolak-balik induksi dilakukan dengan cara mengubah tegangan, frekuensi sumber dan keseimbangan kerapatan fluks secara proposional dapat diimplementasikan. Divais seperti ini umumnya dinamakan Variable Speed Drive (VSD), dengan sistem kendali menggunakan skalar control ataupun vector control. 
Pengendalian motor induksi dengan menggunakan Vector Control selain dapat mengendalikan torsi dan kecepatan secara baik, juga mempunyai keuntungan lain, antara lain :

1. Penggunaanenergimenjadiefisien,

2. Peningkatanfleksebilitasproduksi,

3. Peningkatanumurkomponenmekanik

4. Memudahkanuntukpemeliharaan.

\section{DASAR TEORI}

Metode vector control bertujuan mengendalikan kinerja mesin induksi (motordan generator AC) yang diemulasikan dari kinerja mesin DC. Pada mesin DC, fluksi stator $\psi_{s}$ dihasilkan oleh arus yang dialirkan pada belitan medan stator (fieldwinding) dan fluksi rotor $\psi_{r}$ dihasilkan oleh arus yang dialirkan ke belitan jangkar (armature winding) melalui sikat dan komutator yang selalu menyebabkan posisi medan magnet stator dan medan magnet rotor saling tegak lurus sehingga torsi elektromagnet yang dihasilkan kedua medan magnet tersebut selalu maksimum. Kondisi demikian sering dinamakan berbasis orientasi medan (field orientation). Sekali kondisi field orientation tercapai, maka torsi pada motor DC dapat dikendalikan dengan mudah melalui pengaturan arus jangkar dengan tetap menjaga arus medan konstan (Riyadi Slamet, Penggerak kecepatan variable pada motor induksi tiga fasa berbasis $\mathrm{V} / \mathrm{Hz}$ dan Direct torque control, 2010). Pada Gambar1 ditunjukkan pengendalian kecepatan motor DC yang membutuhkan outer loop untuk mengendalikan kecepatan dan inner loop untuk mengendalikan torsi.

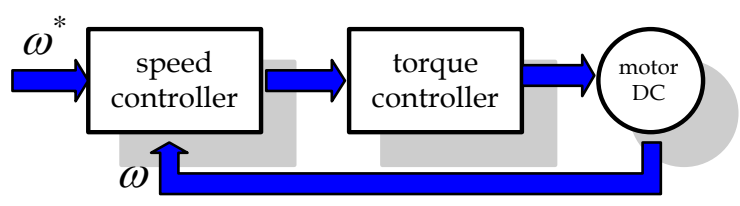

Gambar 1. Pengendalian kecepatan pada motor DC

Dari uraian di atas, Variable Speed Drive yang menggunakan motor DC memiliki beberapa keunggulan, yaitu :

- Pengendaliantorsi dapat dilakukan secara cepat dan akurat

- Responkecepatantinggi

- Rangkaiankendalisederhana

Tetapi beberapa kelemahan juga akan muncul, yaitu :

- Motor DC memerlukan perawatan secara berkala

- Harga motor DC relatifmahal

- Diperlukanencodersebagaiumpanbalik Dengankelemahan-kelemahan di atas, dewasainibanyakdikembangkanVSD yang menggunakan motor AC jenis motor induksi (IM) yang menawarkanbeberapakeunggulan, $\quad \mathrm{di}$ antaranyaukurannyalebihkecil, kokoh, konstruksisederhana, bebasperawatandanhargamurah. Sehinggabanyakdikembangkanteknik- 
teknikmengendalikankecepatan motor AC yang bertujuanmengemulasikankinerja motor DC padaVSDberbasis motor AC (Ojo,O., Consoli, A., danLipo, T.A., 1990, An Improved Model of Saturated Induction Machines).

\subsection{RangkaianEkuivalen}

\section{Motor/Generator Induksi}

Model motor/generator diperoleh dari rangkaian ekivalen motor/generator induksi seperti terlihat pada gambar 2 (a) dan (b).

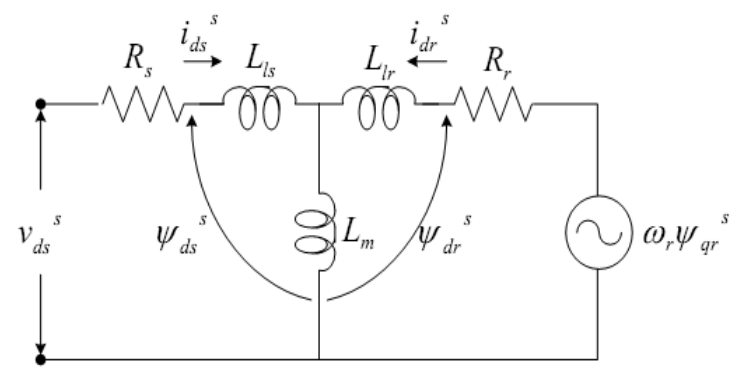

\section{(a) Rangkaian sumbu-ds $s^{s}$}

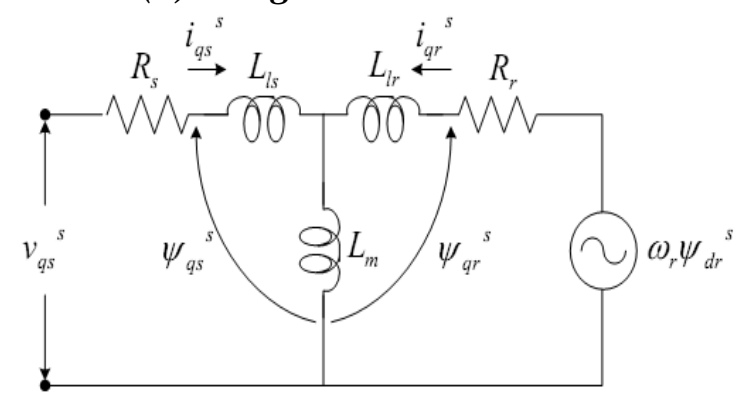

(b). Rangkaian sumbu-qs $s^{s}$

Gambar 2. Rangkaian ekivalen model dinamik motor induksi tiga fasakerangka acuan stator

Dari gambar rangkaian 2, dengan asumsi tegangan rotor motor induksi adalah nol $\left(\mathrm{v}_{\mathrm{qr}}=\mathrm{v}_{\mathrm{dr}}=0\right)$, maka persamaan tegangan stator dan rotor motor induksi adalah :

$$
\begin{aligned}
& \bar{V}_{s}=R_{s} \bar{i}_{s}+\frac{d}{d t} \bar{\psi}_{s}^{[1]} \\
& \bar{V}_{r}=R_{r} \bar{i}_{r}+\frac{d}{d t} \bar{\psi}_{r}+j \omega \bar{\psi}_{r}=0^{[2]}
\end{aligned}
$$

Sedangkan persamaan untuk fluks stator dan rotor adalah :

$$
\bar{\psi}_{s}=L_{s} \bar{i}_{s}+L_{m} \bar{i}_{r}^{[3]}
$$

$\bar{\psi}_{r}=L_{r} \bar{i}_{r}+L_{m} \bar{i}_{s}^{[4]}$

Jika persamaan ${ }^{(4)}$ disubstitusikan ke persamaan ${ }^{(2)}$, maka :

$$
\bar{V}_{r}=\frac{R_{r}}{L_{r}}\left(\bar{\psi}_{r}-L_{m} \bar{i}_{s}\right)+\frac{d}{d t} \bar{\psi}_{r}-j \omega_{r} \bar{\psi}_{r}=0^{[5]}
$$

Sehingga dari persamaan ${ }^{(5)}$ dapat diperoleh persamaan turunan fluks rotor :

$$
\frac{d}{d t} \bar{\psi}_{r}=\left(\frac{R_{r}}{L_{r}} L_{m}\right) \bar{i}_{S}+\left(\frac{R_{r}}{L_{r}}+j \omega_{r}\right) \bar{\psi}_{r}{ }^{[6]}
$$

Jika persamaan ${ }^{(3)}{ }^{(4)}$, dan ${ }^{(6)}$

disubstitusikan ke persamaan (1), maka : $\bar{V}_{s}=\left(R_{s}+\frac{L_{m}{ }^{2} R_{r}}{L_{r}{ }^{2}}\right) \bar{j}_{s}+\left(L_{s}-\frac{L_{m}{ }^{2}}{L_{r}}\right) \frac{d}{d t} \bar{i}_{s}+\left(\frac{L_{m} j \omega_{r}}{L_{r}}-\frac{L_{m} R_{r}}{L_{r}{ }^{2}}\right) \bar{\psi}_{r}$ Dari persamaan ${ }^{(7)}$, persamaan turunan arus stator dapat dinyatakan sebagai berikut $\frac{d}{d t} \bar{i}_{s}=\frac{L_{r}}{L_{s} L_{r}-L_{m}{ }^{2}}\left[\left(-R_{s}+\frac{L_{m}{ }^{2}}{L_{r}{ }^{2}}\right) \bar{i}_{s}+\left(\frac{L_{m}}{L_{r}{ }^{2}} R_{r}-j \frac{L_{m}}{L_{r}} \omega_{r}\right) \bar{\psi}_{r}+\bar{\psi}_{s}\right]$

Sehingga dari persamaan ${ }^{(6)}$ dan ${ }^{(8)}$, muncul model motor induksi dalam kerangka acuan stator (sumbu $\alpha \beta$ ) adalah :

$$
\begin{aligned}
& \frac{d}{d t} i_{s \alpha}=\frac{L_{r}}{L_{s} L_{r}-L_{m}^{2}}\left(-R_{s}-\frac{L_{m} R_{r}}{L_{r}^{2}}\right) i_{s \alpha}+\frac{L_{m}}{\left(\sigma L_{s} L_{r} T_{r}\right)} \psi_{r \alpha}+\frac{L_{m} \omega_{r}}{\sigma L_{s} L_{r}} \psi_{r \beta}+\frac{1}{\sigma L_{s}} V_{s \alpha} \\
& \frac{d}{d t} i_{s \beta}=\frac{L_{r}}{L_{s} L_{r}-L_{m}{ }^{2}}\left(-R_{s}-\frac{L_{m} R_{r}}{L_{r}{ }^{2}}\right) i_{s \beta}-\frac{L_{m} \omega_{r}}{\sigma L_{s} L_{r}} \psi_{r \alpha}+\frac{L_{m}}{\left(\sigma L_{s} L_{r} T_{r}\right)} \psi_{r \beta}+\frac{1}{\sigma L_{s}} V_{s \beta} \\
& \frac{d}{d t} \psi_{r \alpha}=\frac{L_{m}}{T_{r}} i_{s \alpha}-\frac{1}{T_{r}} \psi_{r \alpha}-\omega_{r} \psi_{r \beta}^{[11]} \\
& \frac{d}{d t} \psi_{r \beta}=\frac{L_{m}}{T_{r}} i_{s \beta}+\omega_{r} \psi_{r \alpha}-\frac{1}{T_{r}} \psi_{r \beta}^{[12]}
\end{aligned}
$$


(Nguyen PhungQuang, Jörg-Andreas

Dittrich, "VectorControl of ThreePhase

AC Machine”,September 1965).

\section{Strategi Pengendalian Vektor Kontrol}

Dalam sistem kendali motor berbasis vektor maka tegangan motor harus dimanipulasi dari sistem 3 fasa kedalam kerangka referensi 2 fasa. Ini berarti bahwa arus motor harus diukur secara matematis berubah dari tiga-fase frame kerangka acuan stasioner $(\mathrm{a}, \mathrm{b}, \mathrm{c})$ dari gulungan stator ke dua sumbu tegak lurus kerangka acuan diam atau yang disebut dengan transformasi clarke.

$$
\left[\begin{array}{l}
i_{\alpha} \\
i_{\beta}
\end{array}\right]=\left[\begin{array}{ccc}
1 & -\frac{1}{2} & -\frac{1}{2} \\
0 & \frac{\sqrt{3}}{2} & -\frac{\sqrt{3}}{2}
\end{array}\right]\left[\begin{array}{l}
i_{a} \\
i_{b} \\
i_{c}
\end{array}\right]
$$

Sedangkan matriks transformasi dua fasa menjadi tiga fasa adalah :

$$
\left[\begin{array}{l}
i_{a} \\
i_{b} \\
i_{c}
\end{array}\right]=\sqrt{\frac{2}{3}}\left[\begin{array}{cc}
1 & 0 \\
-\frac{1}{2} & \frac{\sqrt{3}}{2} \\
-\frac{1}{2} & -\frac{\sqrt{3}}{2}
\end{array}\right]\left[\begin{array}{l}
i_{\alpha} \\
i_{\beta}
\end{array}\right]
$$

Demikian pula, tegangan yang akan diterapkan pada motor secara matematis berubah dari frame kerangka acuan diam / tegak lurus diubah kedalam kerangka acuan bergerak dari rotor yang disebut dengan transformasi park (SZABÓ C, Maria IMECS, Ioan Iov, Incze, "VoltHertz Hontrol of the Synchronous Motor
With Ramp Exciting Voltage", Annals of the University of Craiova, Electrical Engineering series, No. 30, 2006)

$$
\left[\begin{array}{c}
i d \\
i q
\end{array}\right]=\left[\begin{array}{cc}
\operatorname{Cos}\left(\omega_{e} t\right) & -\sin \left(\omega_{e} t\right) \\
\sin \left(\omega_{e} t\right) & \operatorname{Cos}\left(\omega_{e} t\right)
\end{array}\right]\left[\begin{array}{c}
i \alpha \\
i \beta
\end{array}\right]
$$

Sedangkan untuk mempresentasikan kerangka acuan bergerak $(d, q)$ menjadi kerangka acuan bergerak $(\alpha, \beta)$, maka digunakan transformasi Park balik

$$
\left[\begin{array}{c}
i \alpha \\
i \beta
\end{array}\right]=\left[\begin{array}{ll}
\operatorname{Cos}\left(\omega_{e} t\right) & \operatorname{Sin}\left(\omega_{e} t\right) \\
-\operatorname{Sin}\left(\omega_{e} t\right) & \operatorname{Cos}\left(\omega_{e} t\right)
\end{array}\right]\left[\begin{array}{l}
i d \\
i q
\end{array}\right]
$$

Pada gambar 3 menunjukkan strategi pengendalian motor induksi 3 fasa dengan sistem vektor SPWM. Pada sistem ini arus 3 fasa motor diambil melalui sensor arus di ubah kedalam referensi melalui persamaan clarke. Output dari persamaan ini adalah sistem 2 fasa dalam kerangka acuan stator (kerangka acuan diam). Komponen ini digunakan sebagai masukan transformasi park yang menghasilkan komponen dq sebagai kerangka acuan bergerak (Zhenyu Yu and David Figoli, "AC Induction Motor Control Using Constant $\mathrm{V} / \mathrm{Hz}$ Principle and Space Vector PWM Technique with TMS320C240", Texas

Instruments Incorporated, April, 1998)

\section{METODOLOGI PENELITIAN}

Untuk menjalankan sistem Vektor PWM inverter maka komponen arus dq 
diumpan balikan melalui referensi arus dq yang diolah melalui PI kontroller untuk menghasilkan transformasi park balik dari dq ke Komponen dimodulasikan dengan sinyal carrier segitiga dalam suatu sistem SPWM (Sinusoidal PulseWidth Modulation) sehingga menghasilkan pulsapulsa kontrol yang sudah terkendali secara vektor untuk menjalankan saklar daya IGBT pada inverter 3 fasa.

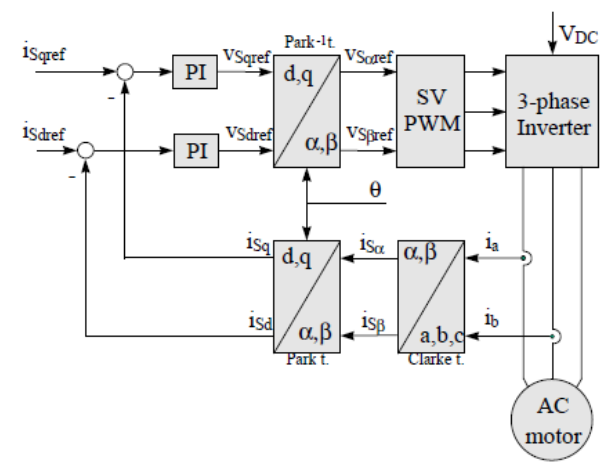

Gambar 3. Skema dasar inverter terkendali vektor

\subsection{Sistem inverter 3 fasa}

Skema yang digunakan untuk pengendalian arus bolak-balik (AC Drive) pada sistem inverter terdiri dari Bridge Rectifier yang disusun dari enam dioda yangdihubungkan jembatan berfungsi untuk mengkonversikan tegangan bolakbalik menjadi tegangan searah (penyearah). Selain dengan penyearah dioda sistem rectifier ini juga bisa menggunakan motode Rectifier SPWM yaitu sistem penyearah yang terkendali melalui penyakalaran IGBT sehingga menghasilkan tegangan DC yang linier dengan sifat gelombang arus sefasa terhadap tegangannya. Untuk meratakan tegangan keluaran rectifier dipasang tapis kapasitor elektronik $\mathrm{C}$ pada terminal keluaran penyearah. Tegangan searah yang dihasilkan dari sistem penyearah adalah :

$$
E_{d}=\frac{3 \sqrt{2}}{\pi} E_{l l}
$$

dengan Ed dan Ell masing-masing adalah tegangan keluaran searah dan tegangan bolak-balik antar fasa-masukan. Tegangan searah keluaran bridge rectifier setelah ditapis dengan kapasitor, selanjutnya dikonversi menjadi tegangan bolak-balik oleh inverter. Untuk mengendalikan saklar IGBT pada sistem inveretr diperlukan driver yang berfungsi memindahkan sinyal kontrol dengan tegangan kecil kedalam rangkaian daya yang bekerja pada tegangan yang relatif lebih besar.

Dengan teknik kendali SPWM maka konfigurasi saklar daya inverter diatas dapatmenghasilkan beberapa kemungkinan pensaklaran seperti pada gambar berikut : 

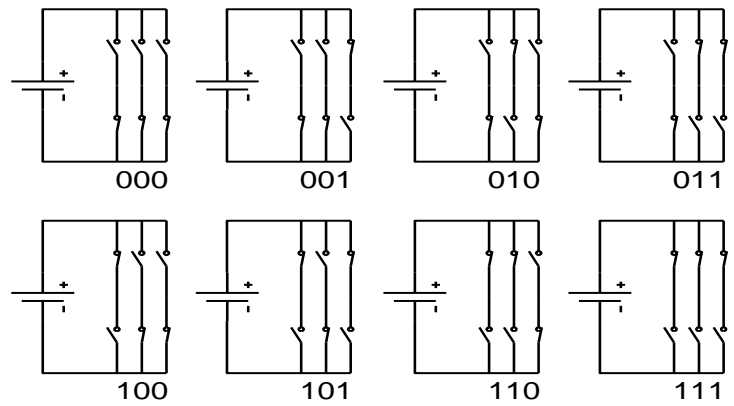

Gb. 5 Konfigurasi saklar daya inverter 3 fasa 3 lengan

\section{HASIL PENELITIAN}

Inverter 3 fasa memiliki enam buah saklar daya (3 lengan) yang masingmasing saklar dapat dikendalikan waktu On dan Off-nya. Setiap pasang saklar (1 lengan) inverter bekerja pada sistem 1 fasa sehingga keduanya harus dikendalikan secara berlawanan, sementara terhadap lengan yang laen masing-masing bekerja berdasarkan pergseran fasa sistem 3 fasa yaitu tergeser $120^{\circ}$ sehingga terbentuk logika pensaklaran inverter 3 fasa ditunjukkan pada tabel 1.

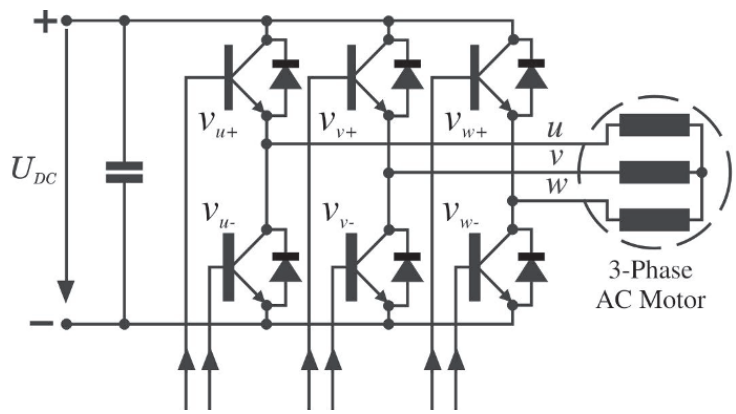

Gb. 6. Inverter 3 fasa dengan saklar
Tabel-1: Konfigurasi Switching dari Three-Leg Voltage Source PWM Converter

\begin{tabular}{|c|c|c|c|c|c|c|c|c|c|}
\hline$S V_{U_{+}}$ & $S V_{U_{*}}$ & $S V_{V_{+}+}$ & $S V_{V \cdot}$ & $S V_{W++}$ & $S V_{W \cdot}$ & $V_{U}$ & $V_{W}$ & $V_{W}$ & Vektor \\
\hline$l$ & 0 & 0 & $l$ & 0 & $l$ & $E$ & 0 & $-E$ & $V_{1}$ \\
\hline$l$ & 0 & $l$ & 0 & 0 & $l$ & 0 & $E$ & $-E$ & $V_{2}$ \\
\hline 0 & $l$ & $l$ & 0 & 0 & $l$ & $-E$ & $E$ & 0 & $V_{3}$ \\
\hline 0 & $l$ & $l$ & 0 & $l$ & 0 & $-E$ & 0 & $E$ & $V_{4}$ \\
\hline 0 & $l$ & 0 & $l$ & $l$ & 0 & 0 & $-E$ & $E$ & $V_{5}$ \\
\hline$l$ & 0 & 0 & $l$ & $l$ & 0 & $E$ & $-E$ & 0 & $V_{6}$ \\
\hline$l$ & 0 & $l$ & 0 & $l$ & 0 & 0 & 0 & 0 & $V_{7}$ \\
\hline 0 & $l$ & 0 & $l$ & 0 & $l$ & 0 & 0 & 0 & $V_{0}$ \\
\hline
\end{tabular}

Konfigurasi switching dari sistem inverter 3 fasa diatas menghasilkan 8 buah vektor yang terdiri dari 6 buah vektor tegangan aktif (active voltage vectors) yang menghasilkan 3 buah tegangan line to line dan 2 buah vektor tegangan pasif (pasive voltage vectors) yang menghasilkan tegangan nol. Suatu vektor tegangan yang berada pada sumbu selalu merepresentasikan tiga buah tegangan lineline tersebut. Perputaran vektor berlawanan dengan arah jarum jam sepanjang $360^{\circ}$ yang merepresentasikan tegangan sinusoidal tiga fasa ideal dengan amplituda ditentukan oleh besarnya magnitute dari vektor tegangan tersebut. Dalam radian masing-masing vektor ditunjukkan pada gambar 7 


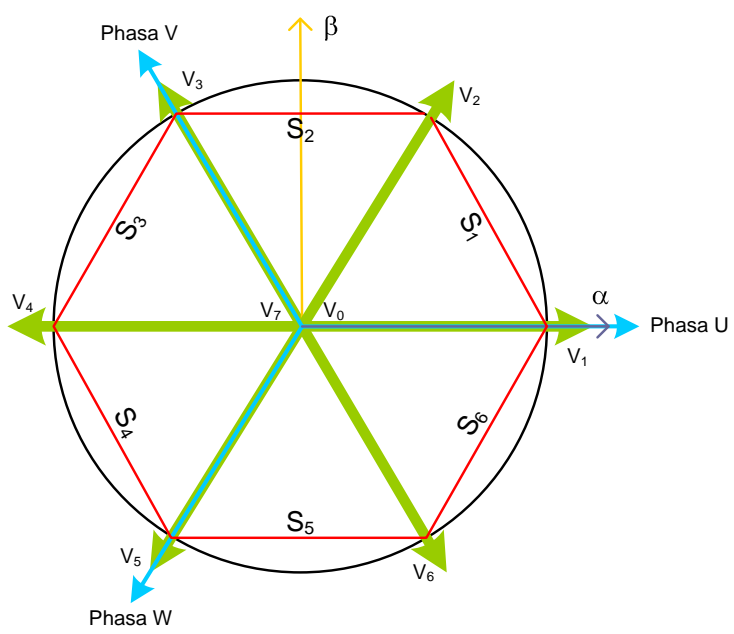

Gb. 7. Vektor-vektor tegangan pada sumbudalam radian

Dari gambar 6 merepresentasikan 8 topologi switching dalam bentuk segi enam (atau Space Vector segi enam). Vektor dalam radian dibagi menjadi 6 sektor. Dari keenam sektor yang menghasilkan 8 logika pensaklaran tersebut dapat dihasilkan nilai tegangan stator motor induksi dengan metode pada gambar 8 .

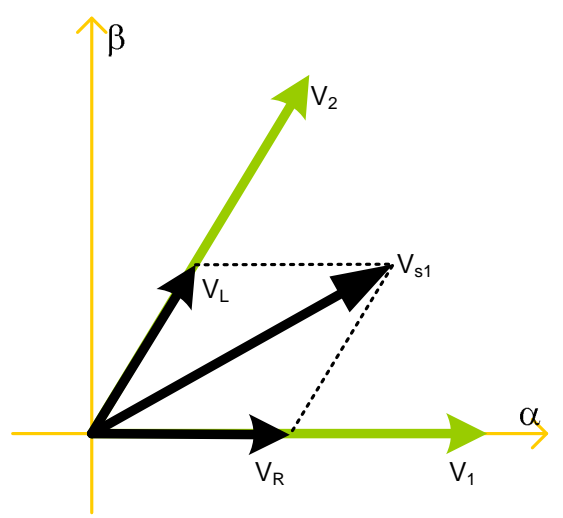

Gb. 8.Realisasinilaitegangan yang dibentukolehduabuah vector
Dari gambar $8, \mathrm{~V}_{\mathrm{s} 1}$ merupakan nilai tegangan yang dihasilkan dari resultan magnitute vektor $\mathrm{V}_{1}$ yang disimbolkan $\mathrm{V}_{\mathrm{R}}$ denganmagnitutevektor2yang disimbolkan dengan $\mathrm{V}_{\mathrm{L}}$. Tegangan $\mathrm{V}_{\mathrm{s} 1}$ bekerja pada sektor 1 yang dibentuk dari 4 buah vektor $\mathrm{V}_{0}, \mathrm{~V}_{1}, \mathrm{~V}_{2}$ dan $\mathrm{V}_{7}$ sehingga menghasilkan logika pensaklaran yang ditunjukkan pada tabel 2

Tabel-2 :logika Switching vector teganganpada sector 1

\begin{tabular}{|l|l|l|l|l|}
\hline & V0 & V1 & V2 & V7 \\
\hline U & $\mathbf{0}$ & $\mathbf{1}$ & $\mathbf{1}$ & $\mathbf{1}$ \\
\hline V & $\mathbf{0}$ & $\mathbf{0}$ & $\mathbf{1}$ & $\mathbf{1}$ \\
\hline W & $\mathbf{0}$ & $\mathbf{0}$ & $\mathbf{0}$ & $\mathbf{1}$ \\
\hline
\end{tabular}

Dalam bentuk logika pulsa yang menjalankan saklar daya IGBT pada inverter ditunjukkan pada gambar 8 .

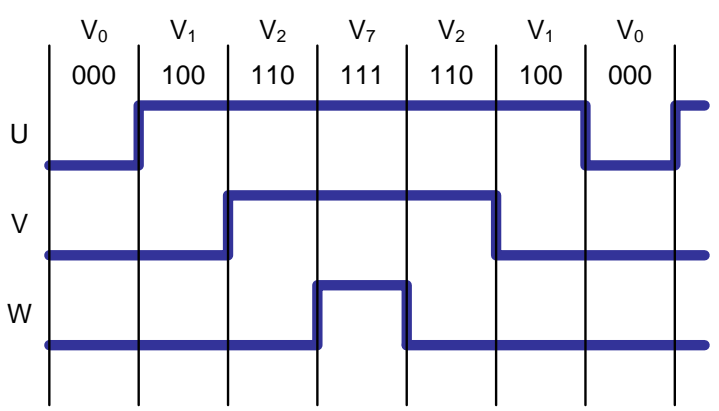

Gb. 9. Logika pulsa vector tegangan pada sector 1

Melalui metode penyaklaran saklar daya inverter dengan pola pengendalian berdasarkan pengendalian masing-masing 
sektor maka meminimalkan rugi-rugi pensaklaran inverter.

Dengan metode vektor kontrol yang menghasilkan 8 topologi penyaklaran seperti yang direpresentasikan pada gambar 8, menghasilkan tegangan fasa netral inverter 3 fasa dengan nilai tegangan berdasar tabel persamaan berikut :

Tabel-3 Nilai tegangan keluaran inverter dengan metode vektor kontrol

\begin{tabular}{|c|c|c|c|c|}
\hline $\begin{array}{c}\text { Switching State } \\
\left(\mathbf{S}_{\mathbf{1}} \mathbf{S}_{2} \mathbf{S}_{3}\right)\end{array}$ & $\boldsymbol{V}_{a N}$ & $\boldsymbol{V}_{b N}$ & $\boldsymbol{V}_{C N}$ & $\begin{array}{c}\text { Sector } \\
\text { number }\end{array}$ \\
\hline $\mathbf{0}$ & 0 & 0 & 0 & 0 (Origin) \\
\hline $\mathbf{1}$ & $\frac{2}{3} V_{D C}$ & $-\frac{1}{3} V_{D C}$ & $-\frac{1}{3} V_{D C}$ & 1 \\
\hline $\mathbf{2}$ & $\frac{1}{3} V_{D C}$ & $\frac{1}{3} V_{D C}$ & $-\frac{2}{3} V_{D C}$ & 2 \\
\hline $\mathbf{3}$ & $-\frac{1}{3} V_{D C}$ & $\frac{2}{3} V_{D C}$ & $-\frac{1}{3} V_{D C}$ & 3 \\
\hline $\mathbf{4}$ & $-\frac{2}{3} V_{D C}$ & $\frac{1}{3} V_{D C}$ & $\frac{1}{3} V_{D C}$ & 4 \\
\hline $\mathbf{5}$ & $-\frac{1}{3} V_{D C}$ & $-\frac{1}{3} V_{D C}$ & $\frac{2}{3} V_{D C}$ & 5 \\
\hline $\mathbf{6}$ & $\frac{1}{3} V_{D C}$ & $-\frac{2}{3} V_{D C}$ & $\frac{1}{3} V_{D C}$ & 6 \\
\hline 7 & 0 & 0 & 0 & 7 (origin) \\
\hline
\end{tabular}

Nilai tegangan tersebut dihasilkan dari suatu alogaritma pulsa penyaklaran invertr space vektor SPWM secara lengkan dari gambar 9.
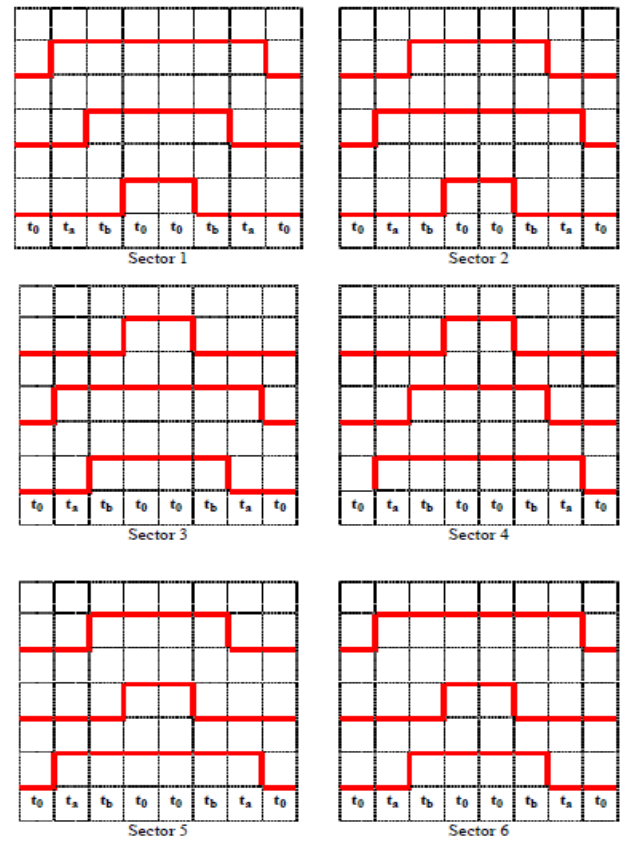

Gb.10. Pola penyaklaran vektor secara berurutan pada masing-masing sektor

6. Kesimpulan

1. Metode vektor kontrol SPWM inverter ini dapat diimplementasikan dengan baik dalam untuk mengendalikan saklar IGBT pada rectifier dan inverter pada aplikasi turbin angin sebagai terobosan untuk pengembangan energi terbarukan

2. Untuk proses realisasi metode kendali Space vector Sinusoidal pulse width Modulation lebih mudah diimplementasikan secara digital yang merepresentasikanpulsa-pulsa penyaklaran pada masing-masing sector. 


\section{Daftar Pustaka}

1. A. K. Sharma, R. A. Gupta, Laxmi Srivastava, "Performance of ann based indirect vector control induction motor drive”, Journal of Theoretical and Applied Information Technology, 2007

2. Musafa,Akhmad,"SimulasiPerancanga nPengendaliVektorArusPada Motor Induksi 3 Fasadengan C-MEX SFUNCTION", Seminar, Universitas Indonesia, 2007.

3. Nguyen PhungQuang, Jörg-Andreas Dittrich, "vector control of three phase AC Machine”, e-ISBN: 978-3-54079029-7, September 1965

4. Ojo,O., Consoli, A., danLipo, T.A., 1990, “An Improved Model of Saturated Induction Machines", IEEE Trans. on Industry Applications, vol 26 no 2, maret, 1990

5. Rahsyid M.H, "Power Electronics: Circuits, Devices and Applications", PT Prehallindo, Jakarta, 1999.

6. Riyadi, Slamet, "Penggerak kecepatan variable pada motor induksi tiga fasa berbasis $\mathrm{V} / \mathrm{Hz}$ dan Direct torque control ",Unika Soegijapranata, 2010

7. Soemarto, "Metode Baru Dalam Identifikasi Parameter Motor Induksi “, Epsilon : Journal of Electrical Engineering and Information Technology Vol. 1, No. 1, July 2003.
8. Trzynadlowsky Andrzej M, "Control of induction motors", department of electrical engineering university of Nevada, 2001

9. Zhenyu $\mathrm{Yu}$ and David Figoli, "AC Induction Motor Control Using Constant $\mathrm{V} / \mathrm{Hz}$ Principle and Space Vector PWM Technique with TMS320C240”, Texas Instruments Incorporated, April, 1998.

10. Simoes, M.G, Farret, F.A, "Renewable energy systems Design and Analysis with Induction Generator",Crc press, Boca raton, Florida, 2004

11. SZABÓ C, Maria IMECS, Ioan Iov, Incze, "Volt-Hertz Hontrol of the Synchronous Motor With Ramp Exciting Voltage", Annals of the University of Craiova, Electrical Engineering series, No. 30, 2006.

12. "Field Orientated Control of 3-Phase AC-Motors", Literature Number: BPRA073, Texas Instruments Europe, February 1998

13. www.st.com, "Flux control simulink and software library of a PMSM", Application note, AN2290, March 2007 